\title{
Higher-Order Free Vibration Analysis of Porous Functionally Graded Plates
}

\author{
Slimane Merdaci ${ }^{1, *}$, Hadj Mostefa Adda ${ }^{2}$, Belghoul Hakima ${ }^{3}$, Rossana Dimitri ${ }^{4, *}$ (D) and Francesco Tornabene 4 (D) \\ 1 Laboratory of Structures and Advanced Materials in Civil Engineering and Public Works, Faculty of \\ Technology, Department of Civil Engineering and Public Works, University of Djillali Liabès of Sidi Bel \\ Abbes, Sidi Bel Abbes 22000, Algeria \\ 2 Laboratory of Industrial Engineering and Sustainable Development, Department Civil Engineering, Institute \\ of Science \& Technology, University of Rélizane, Relizane 48000, Algeria; adda.hadjmostefa@cu-relizane.dz \\ 3 Laboratory of Mechanics Physics of Materials (LMPM), University of Djillali Liabès of Sidi Bel Abbes, \\ Sidi Bel Abbes 22000, Algeria; hakima.belghoul@univ-sba.dz \\ 4 Department of Innovation Engineering, Università del Salento, 73100 Lecce, Italy; \\ francesco.tornabene@unisalento.it \\ * Correspondence: slimane.merdaci@univ-sba.dz (S.M.); rossana.dimitri@unisalento.it (R.D.)
}

check for updates

Citation: Merdaci, S.; Adda, H.M.; Hakima, B.; Dimitri, R.; Tornabene, F. Higher-Order Free Vibration Analysis of Porous Functionally Graded Plates. J. Compos. Sci. 2021, 5, 305. https:// doi.org $/ 10.3390 /$ jcs5110305

Academic Editor:

Thanasis Triantafillou

Received: 10 October 2021

Accepted: 17 November 2021

Published: 21 November 2021

Publisher's Note: MDPI stays neutral with regard to jurisdictional claims in published maps and institutional affiliations.

Copyright: (c) 2021 by the authors. Licensee MDPI, Basel, Switzerland. This article is an open access article distributed under the terms and conditions of the Creative Commons Attribution (CC BY) license (https:// creativecommons.org/licenses/by/ $4.0 /)$.

\begin{abstract}
The present work analyzes the free vibration response of functionally graded (FG) plates made of Aluminum $(\mathrm{Al})$ and Alumina $\left(\mathrm{Al}_{2} \mathrm{O}_{3}\right)$ with different porosity distributions, as usually induced by a manufacturing process. The problem is tackled theoretically based on a higher-order shear deformation plate theory, while proposing a Navier-type approximation to solve the governing equations for simply-supported plates with different porosity distributions in the thickness direction. The reliability of the proposed theory is checked successfully by comparing the present results with predictions available from literature based on further first-order or higher-order theories. A large parametric study is performed systematically to evaluate the effect of different mechanical properties, such as the material indexes, porosity volume fractions, porosity distributions, and lengthto-thickness ratios, on the free vibration response of FG plates, as useful for the design purposes of most engineered materials and composite applications.
\end{abstract}

Keywords: functionally graded plates; free vibration; higher-order plate theory; porosity effect

\section{Introduction}

Among novel materials, functionally graded materials (FGMs) have received special attention in many engineering applications, e.g., thermal coatings and electrical devices [1-6], energy transformation $[7,8]$, biomedical engineering [9,10], optics [11,12], etc., due to their favorable mechanical properties. They represent sophisticated composite materials featuring a gradual and continuous variation of the volume fractions for each constituent by simply tuning a metal and ceramic phase, with a beneficial reduction of possible discontinuities at interfaces, while combining the hardness and workability properties of metal with the thermal, wear and oxidation resistance of the ceramic phase. Due to the large use of these materials in many shell and plate structural members, several higher-order formulations have been developed to study their linear and/or nonlinear behavior, including vibration and buckling problems. With the exception of classical plate theories (CPTs), higher-order plate theories (HSDT) are more appropriate for studying complicated shell geometries, especially with increased thicknesses. Among the available literature, Vel and Batra [13] proposed a three-dimensional closed-form solution for the study of free and forced vibrations of simply-supported (SS) FG rectangular plates. In Ref. [14], the authors analyzed the free vibration response of FG plates based on a third-order shear deformation plate theory combined with a global collocation solution method. In further works [15-17], a higher-order shear and normal deformable plate theory was applied to treat the statics and vibrations of thick rectangular FG elastic plates, accounting for both 
transverse shear and normal deformations, together with the rotatory inertia. Despite the large attention of the literature on the topic, few works have focused, up to now, on the mechanical behavior of porous structures. Rezaei and Saidi [18], for example, investigated the sensitivity of the frequency response of thick porous cellular plates to different porosity levels and distributions by using the Carrera unified formulation (CUF). In Rezaei et al. [19], the same authors studied the free vibrations of isotropic elastic rectangular plates with porosities and undrained conditions, accounting for the fluid-solid coupling interaction. Kamranfard et al. [20] proposed an analytical approach to investigating the buckling and vibration behavior of annular sectorial porous plates subjected to a uniformly distributed in-plane compressive loading. Different eigenvalue problems were solved in closed form in Refs. [21,22] for FG plates in absence of porosity. In detail, a four variable refined plate theory was proposed in [21] to study the free vibrations of FG plates with an arbitrary gradient, whose problem was solved in a closed form and/or numerical form by using a Navier technique and Ritz methods, respectively. A more extended higher-order theory was also proposed in [22] to study moderately thick FG plates, involving the so-called stretching effect, while applying a partitioning procedure to define the transverse displacement field in order to reduce the number of unknowns involved in the problem. Indeed, it is well known from the literature that HSDTs and quasi-3D theoretical approaches are usually expensive due to the introduction of some additional unknown factors within the kinematic field definition throughout the thickness. In such a context, Bîrsan et al. [23,24] studied the deformation and mechanical behavior of sandwich composite beams of FGMs. A three-dimensional model based on finite elements was proposed by Vyacheslav et al. [25] for the free vibration and static analysis of FG sandwich plates. A finite element procedure was also implemented by Mircea et al. [26] and Vyacheslav et al. [27] to determine the effective stiffness properties of multilayered composite beams and to study the free vibrations of FG sandwich flat panels with conventional shell elements.

Starting with the assumptions by Shimpi [28], many shear deformation theories have been employed, using different shape functions. For example, in Refs. [29,30], the authors developed a HSDT for FG sandwich members by means of a sinusoidal function. The same theory was also applied by Tounsi et al. [31] and by Zidi et al. [32] to analyze the thermoelastic bending response of sandwich plates. A manufacturing and sintering process of FGMs can yield random porosities within the pertaining structural components with meaningful effects on their mechanical performances. This is mainly related to the large difference in the solidification temperature [33]. Among the most relevant works on the topic, Wattanasakulpong et al. [34] discuss the porosities occurring within FGMs, as produced by a sequential infiltration technique. Magnucka-Blandzi [35] also studied the dynamic stability of porous circular plates to determine their critical temperatures and to describe the influence of unstable regions within Mathieu's equations. Biot [36] proposed a poroelastic theory to treat the same problem, while introducing both the kinematic and dynamic unknowns. Based on the same theory, Detournay and Cheng [37] extended the constitutive relations for saturated porous structures, as was also used in Ref. [38] for the buckling study of circular thin plates in saturated porous FGMs. Among the most recent works, Ait Yahia et al. [39] applied different higher-order theories to explore the wave propagation in FG porous plates, whereas Mouaici et al. [40] proposed an analytical solution to the vibration problem of FGM plates with porosities, taking into account the exact position of the neutral surfaces. Based on results from literature, the importance of accounting for porosities in the design of FGM structures subjected to static [41-44] or dynamic loads [45,46] is evident even in a nonlocal sense [47]. In such a context, the present work aims at studying the free vibration of SS porous FG plates made of Aluminum (Al) and Alumina $\left(\mathrm{Al}_{2} \mathrm{O}_{3}\right)$, based on a novel HSDT theory, whose material properties are supposed to vary continuously throughout the thickness according to a "power-law" properly modified to include the porosity sensitivity. The Hamilton's principle is here employed to determine the equations of motion associated to the problem, which are solved theoretically by means of a Navier-type solution. Starting with the basic idea from [21], we propose a four-variable 
refined plate theory to handle the problem without any use of shear correction factors, whose accuracy is verified against other higher-order formulations available from literature involving more variables. The potential of the proposed theoretical formulation for FG sandwich plates reinforced with carbon nanotubes (CNTs) would be of particular interest for different plate components, as commonly encountered in many aerospace, marine and automobile structures [48-63], and can be extended to more complicated shell components under different boundary conditions.

A preliminary investigation on the topic can be found in [64], but a more extended sensitivity analysis is performed herein, which includes different material indexes, porosity volume fractions, porosity distributions and length-to-thickness ratios, with promising conclusions for the design purposes of plate components. The numerical results could also serve as useful benchmarks for further computational studies in this field.

\section{Theoretical Formulation}

In the current work, we consider a thick rectangular plate of length $a$, width $b$ and thickness $h$, as illustrated in Figure 1 , along with the Cartesian coordinate system $(x, y, z)$ centered at the mid-plane. With an FG variation of the Young's modulus $E$ and density $\rho$ in the thickness direction in line with the following power-law distribution:

$$
\begin{gathered}
E(z)=\left(E_{c}-E_{m}\right)\left(\frac{1}{2}+\frac{z}{h}\right)^{p}+E_{m}-\frac{\xi}{2}\left(E_{c}+E_{m}\right)\left(1-\frac{2|z|}{h}\right) \\
\rho(z)=\left(\rho_{c}-\rho_{m}\right)\left(\frac{1}{2}+\frac{z}{h}\right)^{p}+\rho_{m}-\frac{\xi}{2}\left(\rho_{c}+\rho_{m}\right)\left(1-\frac{2|z|}{h}\right)
\end{gathered}
$$

where subscripts $c$ and $m$ refer to the ceramic and metal, respectively; $p$ is the volume fraction index, which accounts for the material variation throughout the thickness; $\xi(0 \leq \xi \leq 1)$ stands for the porosity volume fraction. The reader can refer to Refs. $[65,66]$ for an expanded definition of the mechanical properties (1) for an imperfect FG porous plate. A similar porosity distribution is supported consistently by experimental observations [66]. Based on the principle of the multi-step sequential infiltration technique, commonly used to produce FGM samples, the porosities usually localize at the middle zone. At this zone, indeed, it is difficult to infiltrate the materials completely, while at the top and bottom zones, the process of material infiltration can be performed easily and leaves less porosity.
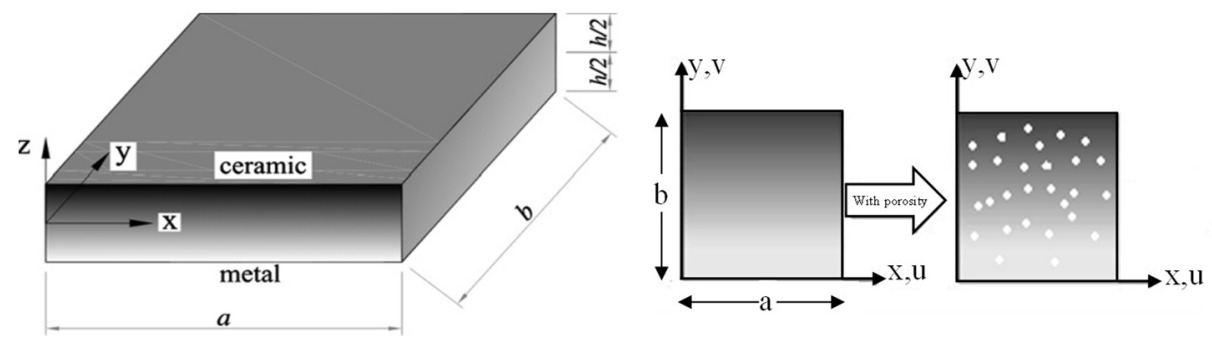

Figure 1. The geometric configuration of the functionally graded (FG) porous plate.

In line with the basic idea from [21,22], the higher-order formulation proposed herein is based on the following displacement field definition $u, v, w$ for an arbitrary point:

$$
\begin{gathered}
u(x, y, z, t)=u_{0}(x, y, t)-z \frac{\partial w_{b}}{\partial x}+\left(\frac{5 z}{4}\left(\frac{1}{5}-\frac{4 z^{2}}{3 h^{2}}\right)\right) \frac{\partial w_{s}}{\partial x} \\
v(x, y, z, t)=v_{0}(x, y, t)-z \frac{\partial w_{b}}{\partial y}+\left(\frac{5 z}{4}\left(\frac{1}{5}-\frac{4 z^{2}}{3 h^{2}}\right)\right) \frac{\partial w_{s}}{\partial y} \\
w(x, y, z, t)=w_{b}(x, y, t)+w_{s}(x, y, t)
\end{gathered}
$$

where $t$ represents the time, $u_{0}$ and $v_{0}$ refer to the axial displacement components in the reference mid-surface of the plate, along the $x$ - and $y$-directions, respectively, and $w_{b}$ and $w_{s}$ stand for the bending and shear components of the transverse displacement $w$. This partitioning procedure leads to a reduction in the number of unknowns, which makes 
the proposed theory much more amenable to mathematical implementations. The strain components associated with the kinematic field (2) are defined as:

$$
\begin{aligned}
& \varepsilon_{x}=\frac{\partial u_{0}}{\partial x}-z \frac{\partial^{2} w_{b}}{\partial x^{2}}+\left(\frac{5 z}{4}\left(\frac{1}{5}-\frac{4 z^{2}}{3 h^{2}}\right)\right) \frac{\partial^{2} w_{s}}{\partial x^{2}} \\
& \varepsilon_{y}=\frac{\partial v_{0}}{\partial y}-z \frac{\partial^{2} w_{b}}{\partial y^{2}}+\left(\frac{5 z}{4}\left(\frac{1}{5}-\frac{4 z^{2}}{3 h^{2}}\right)\right) \frac{\partial^{2} w_{s}}{\partial y^{2}} \\
& \gamma_{x y}=\frac{\partial u_{0}}{\partial y}+\frac{\partial v_{0}}{\partial x}-z\left(2 \frac{\partial^{2} w_{b}}{\partial x \partial y}\right)+\left(\frac{5 z}{4}\left(\frac{1}{5}-\frac{4 z^{2}}{3 h^{2}}\right)\right)\left(2 \frac{\partial^{2} w_{s}}{\partial x \partial y}\right) \\
& \gamma_{y z}=\left(\frac{5}{4}-\frac{5 z^{2}}{h^{2}}\right) \frac{\partial w_{s}}{\partial y} \\
& \gamma_{x z}=\left(\frac{5}{4}-\frac{5 z^{2}}{h^{2}}\right) \frac{\partial w_{s}}{\partial x} \\
& \varepsilon_{z}=0
\end{aligned}
$$

whereby the constitutive relations for a linear elastic isotropy are assumed at local points as follows:

$$
\left\{\begin{array}{c}
\sigma_{x} \\
\sigma_{y} \\
\tau_{x y} \\
\tau_{y z} \\
\tau_{z x}
\end{array}\right\}=\left[\begin{array}{ccccc}
Q_{11} & Q_{12} & 0 & 0 & 0 \\
Q_{21} & Q_{22} & 0 & 0 & 0 \\
0 & 0 & Q_{33} & 0 & 0 \\
0 & 0 & 0 & Q_{44} & 0 \\
0 & 0 & 0 & 0 & Q_{55}
\end{array}\right]\left\{\begin{array}{c}
\varepsilon_{x} \\
\varepsilon_{y} \\
\gamma_{x y} \\
\gamma_{y z} \\
\gamma_{z x}
\end{array}\right\}
$$

relating the stress components $\left(\sigma_{x}, \sigma_{y}, \tau_{x y}, \tau_{y z}, \tau_{y x}\right)$ and the strain components $\left(\varepsilon_{x}, \varepsilon_{y}, \gamma_{x y}\right.$, $\left.\gamma_{y z}, \gamma_{y x}\right)$ by means of the elastic coefficients $Q_{i j}$, defined as:

$$
Q_{11}=Q_{22}=\left(\frac{E(z)}{1-v^{2}}\right), Q_{12}=Q_{21}=\left(\frac{v E(z)}{1-v^{2}}\right), Q_{33}=Q_{44}=Q_{55}=G(z), G(z)=\left(\frac{E(z)}{2(1+v)}\right)
$$

The elastic moduli $E, G$, the Poisson's ratio $v$ and the elastic coefficients $Q_{i j}$ vary throughout the thickness, according to Equation (1).

\section{Equations of Motion}

The governing equations of the problem are computed by means of Hamilton's principle, which can be stated in the time interval $[0, t]$, as in Ref. [61]:

$$
\int_{0}^{t}(\delta U-\delta K) d t=0
$$

with $\delta U, \delta K$ being the variation of the strain energy and kinetic energy, respectively. More specifically, the strain energy is defined in variational form as:

$\delta U=\int_{A}\left[N_{x} \delta \varepsilon_{x}^{0}+N_{y} \delta \varepsilon_{y}^{0}+N_{x y} \delta \varepsilon_{x y}^{0}+M_{x}^{b} \delta k_{x}^{b}+M_{y}^{b} \delta k_{y}^{b}+M_{x y}^{b} \delta k_{x y}^{b}+M_{x}^{s} \delta k_{x}^{s}+M_{y}^{s} \delta k_{y}^{s}+M_{x y}^{s} \delta k_{x y}^{s}+S_{y z}^{s} \delta \gamma_{y z}^{s}+S_{x z}^{s} \delta \gamma_{x z}^{s}\right] d A$

where:

$$
\begin{aligned}
& \varepsilon_{x}^{0}=\frac{\partial u_{0}}{\partial x}, \varepsilon_{y}^{0}=\frac{\partial v_{0}}{\partial y}, \gamma_{x y}^{0}=\frac{\partial u_{0}}{\partial y}+\frac{\partial v_{0}}{\partial x} \\
& k_{x}^{b}=-\frac{\partial^{2} w_{b}}{\partial x^{2}}, k_{y}^{b}=-\frac{\partial^{2} w_{b}}{\partial y^{2}}, k_{x y}^{b}=-2 \frac{\partial^{2} w_{b}}{\partial x \partial y} \\
& k_{x}^{s}=\frac{\partial^{2} w_{s}}{\partial x^{2}}, k_{y}^{s}=\frac{\partial^{2} w_{s}}{\partial y^{2}}, k_{x y}^{s}=2 \frac{\partial^{2} w_{s}}{\partial x \partial y} \\
& \gamma_{y z}^{s}=\frac{\partial w_{s}}{\partial y}, \gamma_{x z}^{s}=\frac{\partial w_{s}}{\partial x}
\end{aligned}
$$

whereas $A$ refers to the top surface. Thus, the stress resultants $N, M$, and $S$ take the following form:

$$
\begin{gathered}
{\left[\begin{array}{ccc}
N_{x}, & N_{y,} & N_{x y} \\
M_{x,}^{b} & M_{y,}^{b} & M_{x y}^{b} \\
M_{x}^{s}, & M_{y,}^{s} & M_{x y}^{s}
\end{array}\right]=\int_{-h / 2}^{h / 2}\left(\begin{array}{c}
\sigma_{x} \\
\sigma_{y} \\
\tau_{x y}
\end{array}\right)(1 z f(z)) d z,} \\
\left(S_{x z}^{s}, S_{y z}^{s}\right)=\int_{-h / 2}^{h / 2}\left(\tau_{x z}, \tau_{y z}\right) g(z) d z .
\end{gathered}
$$


being

$$
f(z)=\frac{5 z}{4}\left(\frac{1}{5}-\frac{4 z^{2}}{3 h^{2}}\right), g(z)=\frac{5}{4}-\frac{5 z^{2}}{h^{2}}
$$

In addition, the kinetic energy can be defined in variational form as:

$$
\delta K=\int_{-h / 2}^{h / 2} \int_{A} \rho(z)(\ddot{u} \delta u+\ddot{v} \delta v+\ddot{w} \delta w) d A d z
$$

where $\ddot{u}, \ddot{v}, \ddot{w}$ stand for the axial accelerations along the $x, y, z$ directions, and $\left(I_{1}, I_{2}, I_{3}, I_{4}, I_{5}, I_{6}\right)$ are the inertial mass defined as:

$$
\left(I_{1}, I_{2}, I_{3}, I_{4}, I_{5}, I_{6}\right)=\int_{-h / 2}^{h / 2}\left(1, z, z^{2}, f(z), z f(z), f^{2}(z)\right) \rho(z) d z
$$

By substituting $\delta U$ and $\delta K$ from Equations (6) and (8) into Equation (5), after integrating by parts the displacement gradients, and by setting the coefficients of $\delta u, \delta v, \delta w_{b}$, and $\delta w_{s}$ equal to zero separately, we determine the following equations of motion:

$$
\begin{gathered}
\delta u: \frac{\partial N_{x}}{\partial x}+\frac{\partial N_{x y}}{\partial y}=I_{1} \ddot{w}_{0}-I_{2} \frac{\partial \ddot{w}_{b}}{\partial x}-I_{4} \frac{\partial \ddot{w}_{s}}{\partial x} \\
\delta v: \frac{\partial N_{x y}}{\partial x}+\frac{\partial N_{y}}{\partial y}=I_{1} \ddot{w}_{0}-I_{2} \frac{\partial \ddot{w}_{b}}{\partial y}-I_{4} \frac{\partial \ddot{w}_{s}}{\partial y} \\
\delta w_{b}: \frac{\partial^{2} M_{x}^{b}}{\partial x^{2}}+2 \frac{\partial^{2} M_{x y}^{b}}{\partial x y y}+\frac{\partial^{2} M_{y}^{b}}{\partial y^{2}}=I_{1}\left(\ddot{w}_{b}+\ddot{w}_{s}\right)+I_{2}\left(\frac{\partial \ddot{u}}{\partial x}+\frac{\partial \ddot{v}}{\partial y}\right)-I_{3}\left(\frac{\partial^{2} \ddot{w}_{b}}{\partial x^{2}}+\frac{\partial^{2} \ddot{w}_{b}}{\partial y^{2}}\right)-I_{5}\left(\frac{\partial^{2} \ddot{w}_{s}}{\partial x^{2}}+\frac{\partial^{2} \ddot{w}_{s}}{\partial y^{2}}\right) \\
\delta w_{s}: \frac{\partial^{2} M_{x}^{s}}{\partial x^{2}}+2 \frac{\partial^{2} M_{x y}^{s}}{\partial x \partial y}+\frac{\partial^{2} M_{y}^{s}}{\partial y^{2}}+\frac{\partial S_{x z}^{s}}{\partial x}+\frac{\partial S_{y z}^{s}}{\partial y}=I_{1}\left(\ddot{w}_{b}+\ddot{w}_{s}\right)+I_{4}\left(\frac{\partial \ddot{u}}{\partial x}+\frac{\partial \ddot{v}}{\partial y}\right)-I_{5}\left(\frac{\partial^{2} \ddot{w}_{b}}{\partial x^{2}}+\frac{\partial^{2} \ddot{w}_{b}}{\partial y^{2}}\right)-I_{6}\left(\frac{\partial^{2} \ddot{w}_{s}}{\partial x^{2}}+\frac{\partial^{2} \ddot{w}_{s}}{\partial y^{2}}\right)
\end{gathered}
$$

Thus, we determine the stress resultants by combining Equations (3) and (4) and by integrating throughout the thickness direction, namely:

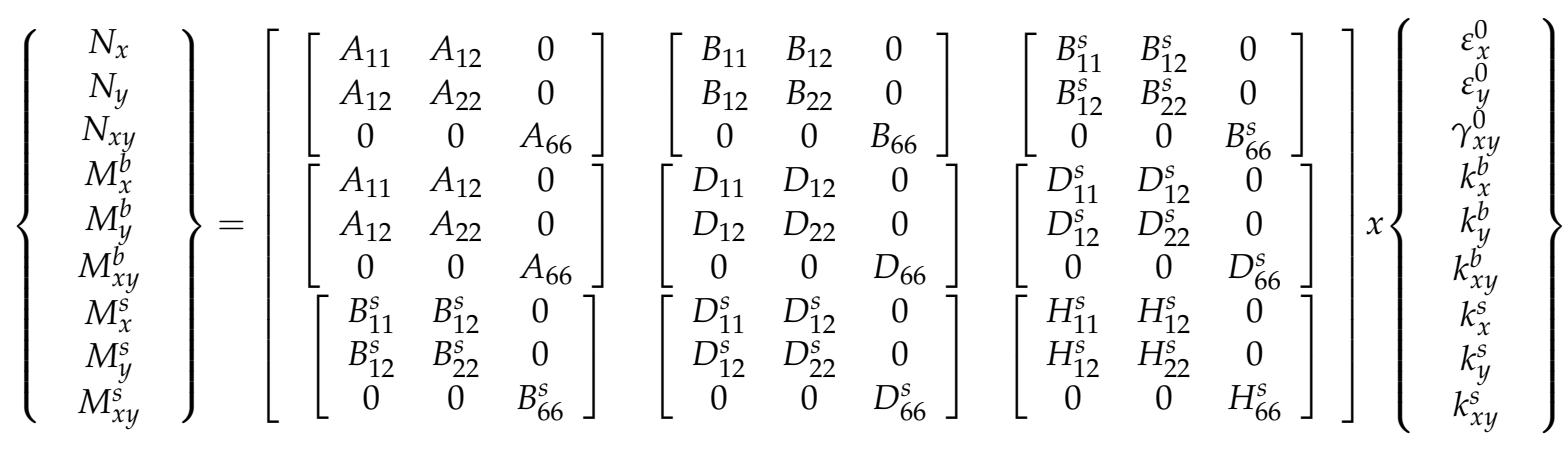

and

$$
\left\{\begin{array}{l}
S_{x z}^{s} \\
S_{y z}^{s}
\end{array}\right\}=\left[\begin{array}{cc}
A_{44}^{s} & 0 \\
0 & A_{55}^{s}
\end{array}\right] x\left\{\begin{array}{l}
\gamma_{x z} \\
\gamma_{y z}
\end{array}\right\}
$$

where

$$
\begin{aligned}
& \left\{A_{i j}, B_{i j}, D_{i j}\right\}=\int_{-h / 2}^{h / 2}\left(1, z, z^{2}\right) Q_{i j} d z \quad(i, j=1,2,3) \\
& \left\{B_{i j}^{s}, D_{i j}^{s}, H_{i j}^{s}\right\}=\int_{-h / 2}^{h / 2}\left(f(z), z f(z), f^{2}(z)\right) Q_{i j} d z \quad(i, j=1,2,3) \\
& \left\{A_{i j}^{s}\right\}=\int_{-h / 2}^{h / 2}\left(g^{2}(z)\right) Q_{i j} d z, \quad(i, j=4,5)
\end{aligned}
$$




\section{Analytical Solution}

The response of a rectangular plate is well-known to vary with the selected boundary support. In this paper, we focus on SS FG plates, and we check for the exact Navier-type solution to the problem. In agreement with the selected boundary conditions, we consider the following kinematic solution for $\left(u_{0}, v_{0}, w_{b}, w_{s}\right)$ :

$$
\left\{\begin{array}{c}
u_{0} \\
v_{0} \\
w_{b} \\
w_{s}
\end{array}\right\}=\sum_{m=1}^{\infty} \sum_{n=1}^{\infty}\left\{\begin{array}{c}
U_{m n} e^{i \omega t} \cos (\lambda x) \sin (\mu y) \\
V_{m n} e^{i \omega t} \sin (\lambda x) \cos (\mu y) \\
W_{b m n} e^{i \omega t} \sin (\lambda x) \sin (\mu y) \\
W_{s m n} e^{i \omega t} \sin (\lambda x) \sin (\mu y)
\end{array}\right\}
$$

where $\lambda=m \pi / a$ and $\mu=n \pi / b$, whereas $m$ and $n$ refer to the mode numbers, $U_{m n}, V_{m n}, W_{b m n}, W_{s m n}$, refer to the amplitudes, and $\omega$ is the free vibration frequency of the plate, $\sqrt{i}=-1$ being the imaginary unit. We substitute Equations (12) and (17) into Equation (13) to obtain the following system of equations:

$$
\left(\mathbf{K}-\omega^{2} \mathbf{M}\right) \Delta=\mathbf{0},
$$

where $\mathbf{K}$ and $\mathbf{M}$ stand for the stiffness and mass matrices, respectively, that yield the following explicit form:

$$
\left(\left[\begin{array}{llll}
a_{11} & a_{12} & a_{13} & a_{14} \\
a_{12} & a_{22} & a_{23} & a_{24} \\
a_{13} & a_{23} & a_{33} & a_{34} \\
a_{14} & a_{24} & a_{34} & a_{44}
\end{array}\right]-\omega^{2}\left[\begin{array}{cccc}
I_{1} & 0 & -\lambda I_{2} & -\lambda I_{4} \\
0 & I_{1} & -\mu I_{2} & -\mu I_{4} \\
-\lambda I_{2} & -\mu I_{2} & I_{1}+I_{3}\left(\lambda^{2}+\mu^{2}\right) & I_{5}\left(\lambda^{2}+\mu^{2}\right) \\
-\lambda I_{4} & -\mu I_{4} & I_{5}\left(\lambda^{2}+\mu^{2}\right) & I_{6}\left(\lambda^{2}+\mu^{2}\right)
\end{array}\right]\right)\left\{\begin{array}{c}
U_{m n} \\
V_{m n} \\
W_{b m n} \\
W_{s m n}
\end{array}\right\}=\left\{\begin{array}{l}
0 \\
0 \\
0 \\
0
\end{array}\right\}
$$

with

$$
\begin{aligned}
& a_{11}=-\left(A_{11} \lambda^{2}+A_{66} \mu^{2}\right) ; a_{12}=-\lambda \mu\left(A_{12}+A_{66}\right) ; a_{13}=\lambda\left(B_{11} \lambda^{2}+\left(B_{12}+2 B_{66}\right) \mu^{2}\right) ; a_{14}=\lambda\left(B_{11}^{s} \lambda^{2}+\left(B_{12}^{s}+2 B_{66}^{s}\right) \mu^{2}\right) \\
& a_{21}=a_{12} ; a_{22}=-\left(A_{66} \lambda^{2}+A_{22} \mu^{2}\right) ; a_{23}=\mu\left(\left(B_{12}+2 B_{66}\right) \lambda^{2}+B_{22} \mu^{2}\right) ; a_{24}=\mu\left(\left(B_{12}^{s}+2 B_{66}^{s}\right) \lambda^{2}+B_{22}^{s} \mu^{2}\right) \\
& a_{31}=a_{13} ; a_{32}=a_{23} ; a_{33}=-\left(D_{11} \lambda^{4}+2\left(D_{12}+2 D_{66}\right) \lambda^{2} \mu^{2}+D_{22} \mu^{4}\right) ; a_{34}=-\left(D_{11}^{s} \lambda^{4}+2\left(D_{12}^{s}+2 D_{66}^{s}\right) \lambda^{2} \mu^{2}+D_{22}^{s} \mu^{4}\right) \\
& a_{41}=a_{14} ; a_{42}=a_{24} ; a_{43}=a_{34} ; a_{44}=-\left(H_{11}^{s} \lambda^{4}+2\left(H_{12}^{s}+2 H_{66}^{s}\right) \lambda^{2} \mu^{2}+H_{22}^{s} \mu^{4}+A_{55}^{s} \lambda^{2}+A_{44}^{s} \mu^{2}\right)
\end{aligned}
$$

Equation (19) represents the general version of the free vibration problem for FG plates, which can be reduced to a static problem by neglecting the mass matrix or to a simple free vibration problem by omitting the in-plane loads.

\section{Numerical Examples}

We now present some numerical examples in order to test the performance of the proposed theory for free vibration problems of SS isotropic homogeneous and FG plates. The following dimensionless quantities are introduced for the study:

$$
\widetilde{\omega}=\omega \mathrm{h} \sqrt{\rho_{\mathrm{c}} / \mathrm{E}_{\mathrm{c}}}, \hat{\omega}=(\omega \mathrm{h}) \sqrt{\rho_{\mathrm{m}} / \mathrm{E}_{\mathrm{m}}}, \bar{\omega}=\left(\omega \mathrm{a}^{2} / \mathrm{h}\right) \sqrt{\rho_{\mathrm{c}} / \mathrm{E}_{\mathrm{c}}}
$$

Based on the system of equations and the solution procedure discussed in the previous sections, the numerical results are presented in what follows for an $\mathrm{Al} / \mathrm{Al}_{2} \mathrm{O}_{3} \mathrm{FG}$ plate made of Aluminum (as metal) and Alumina (as ceramic), whose mechanical properties are summarized in Table 1.

Table 1. Material properties for an FG plate.

\begin{tabular}{ccc}
\hline Properties & Aluminum $(\mathrm{Al})$ & Alumina $\left(\mathrm{Al}_{2} \mathbf{O}_{3}\right)$ \\
\hline Young's modulus $\left(\mathrm{N} / \mathrm{m}^{2}\right)$ & $70 \times 10^{9}$ & $38 \times 10^{8}$ \\
\hline Poisson's ratio & 0.3 & 0.3 \\
\hline Mass density $\left(\mathrm{kg} / \mathrm{m}^{3}\right)$ & 2702 & 3800 \\
\hline
\end{tabular}


To examine the accuracy of the proposed procedure, the fundamental frequencies of the square plate, as obtained in the present study, are evaluated comparatively in Table 2 with respect to predictions from the literature (see Benachour et al. [21], Belabed et al. [22], Rezaei et al. [65] and Askari et al. [66]) for different geometry ratios $a / h$. The perfect agreement between our results and the reference ones from the literature, for each selected parameter $a / h$ and $p$, confirms the reliability and accuracy of the proposed method to treat the problem. A decreased value of both $a / h$ and $p$ also gets higher frequencies $\widetilde{\omega}$, which corresponds to an overall increase of the structural stiffness. Note that a similar formulation could be extended in a further work to more complex boundary conditions of curved structures in line with $[67,68]$.

Table 2. Fundamental frequency $\widetilde{\omega}$ for SS FG square plates.

\begin{tabular}{|c|c|c|c|c|}
\hline \multirow{2}{*}{$a / h$} & \multirow{2}{*}{ Method } & \multicolumn{3}{|c|}{$p$} \\
\hline & & 0 & 1 & 4 \\
\hline \multirow{5}{*}{20} & Ref. [21] & 0.0148 & 0.0113 & 0.0098 \\
\hline & Ref. [22] & 0.0148 & 0.0113 & 0.0098 \\
\hline & Ref. [65] & 0.0148 & 0.0113 & 0.0098 \\
\hline & Ref. [66] & 0.0148 & 0.0113 & 0.0098 \\
\hline & Proposed formulation & 0.0148 & 0.0113 & 0.0098 \\
\hline \multirow{5}{*}{10} & Ref. [21] & 0.0576 & 0.0441 & 0.0380 \\
\hline & Ref. [22] & 0.0578 & 0.0449 & 0.0389 \\
\hline & Ref. [65] & 0.0578 & 0.0442 & 0.0383 \\
\hline & Ref. [66] & 0.0577 & 0.0442 & 0.0380 \\
\hline & Proposed formulation & 0.0577 & 0.0442 & 0.0381 \\
\hline \multirow{5}{*}{5} & Ref. [21] & 0.2112 & 0.1628 & 0.1375 \\
\hline & Ref. [22] & 0.2121 & 0.1640 & 0.1383 \\
\hline & Ref. [65] & 0.2127 & 0.1630 & 0.1405 \\
\hline & Ref. [66] & 0.2112 & 0.1631 & 0.1377 \\
\hline & Proposed formulation & 0.2113 & 0.1631 & 0.1378 \\
\hline
\end{tabular}

Below, in Table 3, we summarize the results in terms of four fundamental frequencies, for the same SS square FG plate, under two different porosity factors $(\xi=0.1$ and $\xi=0.2)$.

Table 3. Fundamental frequency $\hat{\omega}$ for the SS FG square plate $(p=1$ and $a / h=20)$.

\begin{tabular}{cccccc}
\hline \multirow{2}{*}{ Porosity } & \multirow{2}{*}{ Method } & \multicolumn{4}{c}{ Mode $(\boldsymbol{m}, \boldsymbol{n})$} \\
\cline { 2 - 5 } & & $\mathbf{( 1 , \mathbf { 1 }}$ & $\mathbf{( 1 , 2 )}$ & $\mathbf{( 2 , 2 )}$ & $\mathbf{( 1 , 3 )}$ \\
\hline \multirow{3}{*}{$\xi=0.1$} & Ref. [65] & 0.0224 & 0.0553 & 0.0874 & 0.1085 \\
\cline { 2 - 5 } & Ref. [66] & 0.0223 & 0.0552 & 0.0873 & 0.1083 \\
\cline { 2 - 5 } & Proposed formulation & 0.0224 & 0.0554 & 0.0874 & 0.1084 \\
\hline \multirow{3}{*}{$\xi=0.2$} & Ref. [65] & 0.0225 & 0.0555 & 0.0879 & 0.1091 \\
\cline { 2 - 6 } & Ref. [66] & 0.0224 & 0.0554 & 0.0877 & 0.1087 \\
\cline { 2 - 5 } & Proposed formulation & 0.0225 & 0.0555 & 0.0879 & 0.1089 \\
\hline
\end{tabular}


Our results are successfully compared with findings from Refs. [65,66], based on a more simplified first-order shear deformation theoretical assumption. A certain sensitivity of each fundamental frequency can be observed for a varying porosity factor $\xi$, with a clear reduction in frequency for an increasing porosity level, due to an increased structural flexibility.

Another comparative evaluation of the proposed theory against the literature is summarized in Table 4 for a rectangular plate $\mathrm{Al} / \mathrm{Al}_{2} \mathrm{O}_{3}$ with $b / a=2$, for three different vibration modes, with an excellent agreement between our results and predictions by Mouaici et al. [56], based on a different hyperbolic shear deformation theory. This confirms once again the reliability of our model in gaining accurate results, even in the presence of manufacturing defects such as porosities.

Table 4. Comparison of natural frequencies $\bar{\omega}$ for a rectangular plate with $\mathrm{Al} / \mathrm{Al}_{2} \mathrm{O}_{3}$ and $p=1$.

\begin{tabular}{|c|c|c|c|c|c|}
\hline \multirow{2}{*}{ Mode $(m, n)$} & \multirow{2}{*}{$a / h$} & \multirow{2}{*}{ Model } & \multirow{2}{*}{$\begin{array}{c}\text { Perfect } \\
\xi=0\end{array}$} & \multicolumn{2}{|c|}{ Imperfect } \\
\hline & & & & $\xi=0.1$ & $\xi=0.2$ \\
\hline \multirow{4}{*}{$(1,1)$} & \multirow{2}{*}{5} & Ref. [56] & 2.6476 & 2.5934 & 2.5150 \\
\hline & & Proposed formulation & 2.6475 & 2.5930 & 2.5140 \\
\hline & \multirow{2}{*}{10} & Ref. [56] & 2.7937 & 2.7328 & 2.6452 \\
\hline & & Proposed formulation & 2.7937 & 2. 7320 & 2.6448 \\
\hline \multirow{4}{*}{$(1,2)$} & \multirow{2}{*}{5} & Ref. [56] & 4.0782 & 3.9982 & 3.8821 \\
\hline & & Proposed formulation & 4.0781 & 3.9978 & 3.8818 \\
\hline & \multirow{2}{*}{10} & Ref. [56] & 4.4193 & 4.3243 & 4.1875 \\
\hline & & Proposed formulation & 4.4192 & 4.3224 & 4.1863 \\
\hline \multirow{4}{*}{$(1,3)$} & \multirow{2}{*}{5} & Ref. [56] & 6.2664 & 6.1508 & 6.9033 \\
\hline & & Proposed formulation & 6.2663 & 6.1502 & 6.9024 \\
\hline & \multirow{2}{*}{10} & Ref. [56] & 7.0516 & 5.9821 & 6.6891 \\
\hline & & Proposed formulation & 7.0515 & 5.9818 & 6.6886 \\
\hline
\end{tabular}

As is also visible in Figure 2, an increased material power index enables a monotonic reduction of the natural frequencies for both perfect and imperfect FG plates, which is even more pronounced for an increased porosity level, $\xi$. In this case, we evaluate only the first vibration mode of the structure, accounting for both a perfect or imperfect structure with even distributions of porosities. As expected, a perfect structure features higher frequencies with respect to an imperfect one, under the same assumptions for the power law index $p$.

The further parametric investigation accounts for the sensitivity of the first dimensionless frequency $\bar{\omega}$ for an increased geometrical ratio, $b / a$, a fixed ratio, $a / h$, while considering a perfect structure (i.e., $\xi=0$ ) or an imperfect structure with uneven defects, under the assumptions $\xi=0.1$ or $\xi=0.2$ (see Figure 3). Additionally, in this case, it is worth noticing the monotone decrease of the dimensionless frequency for an increasing geometrical ratio, $b / a$, but this behavior seems to be slightly affected by uneven defects within the structure compared to the reference perfect case. 


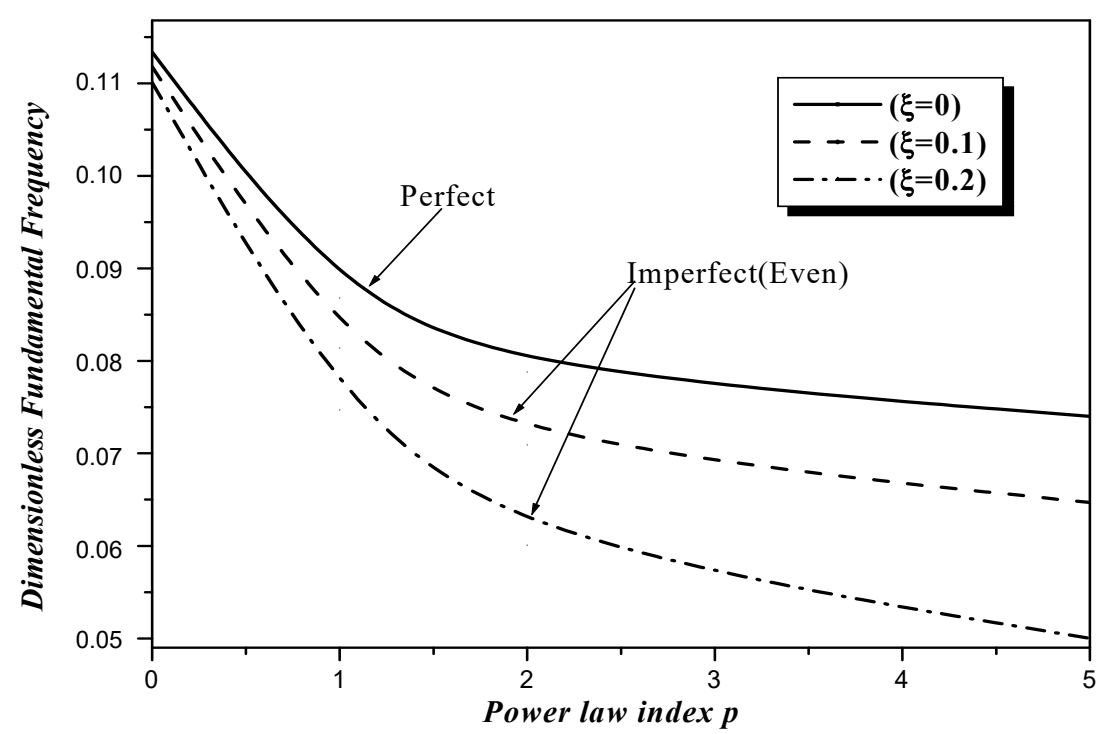

Figure 2. The dimensionless frequency $\bar{\omega}$ vs. the material power index $p$ for FG plates with different porosity factors $(b / a=1$ and $a / h=10)$.

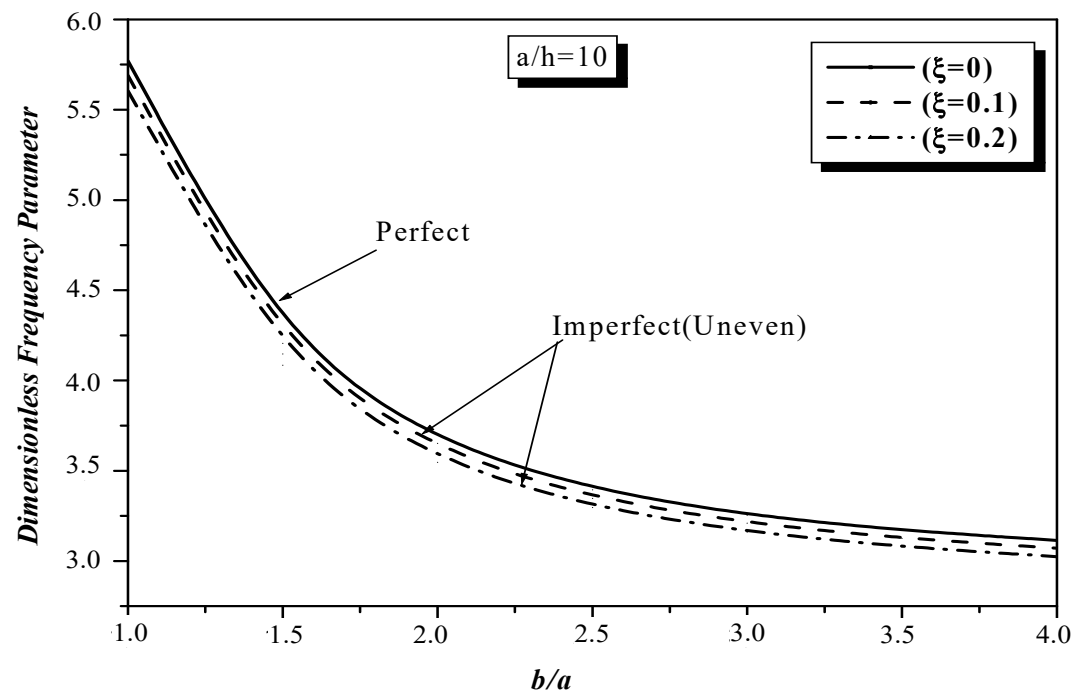

Figure 3. The dimensionless frequency $\bar{\omega}$ vs. the geometrical ratio $b / a$ for FG plates with different porosity factors.

In Figure 4, we show the influence of the exponent $p$ and the thickness ratio, $a / h$, on the dimensionless frequency $\bar{\omega}$ for FG perfect $(\xi=0)$ and imperfect $(\xi=0.1$ and 0.2$)$ plates, with a monotone reduction in the frequency response for increasing values of $p$, for a given geometry and porosity. Moreover, an increased ratio $a / h$ gets an increased dimensionless frequency $\bar{\omega}$ for each fixed graduation level $p$, as is also observable in the plots of Figure 5. This variation is more remarkable when $a / h<10$ for both perfect and imperfect structures, and it tends to reduce for thickness ratios higher than 10. In any case, the highest frequency values are expectable in perfect structures, whose predictions could overestimate the effective results of actual structures in the presence of dislocated defects. This confirms the importance of developing predictive models including possible defects or voids within materials, especially when featuring composite microstructural natures such as FG materials. 

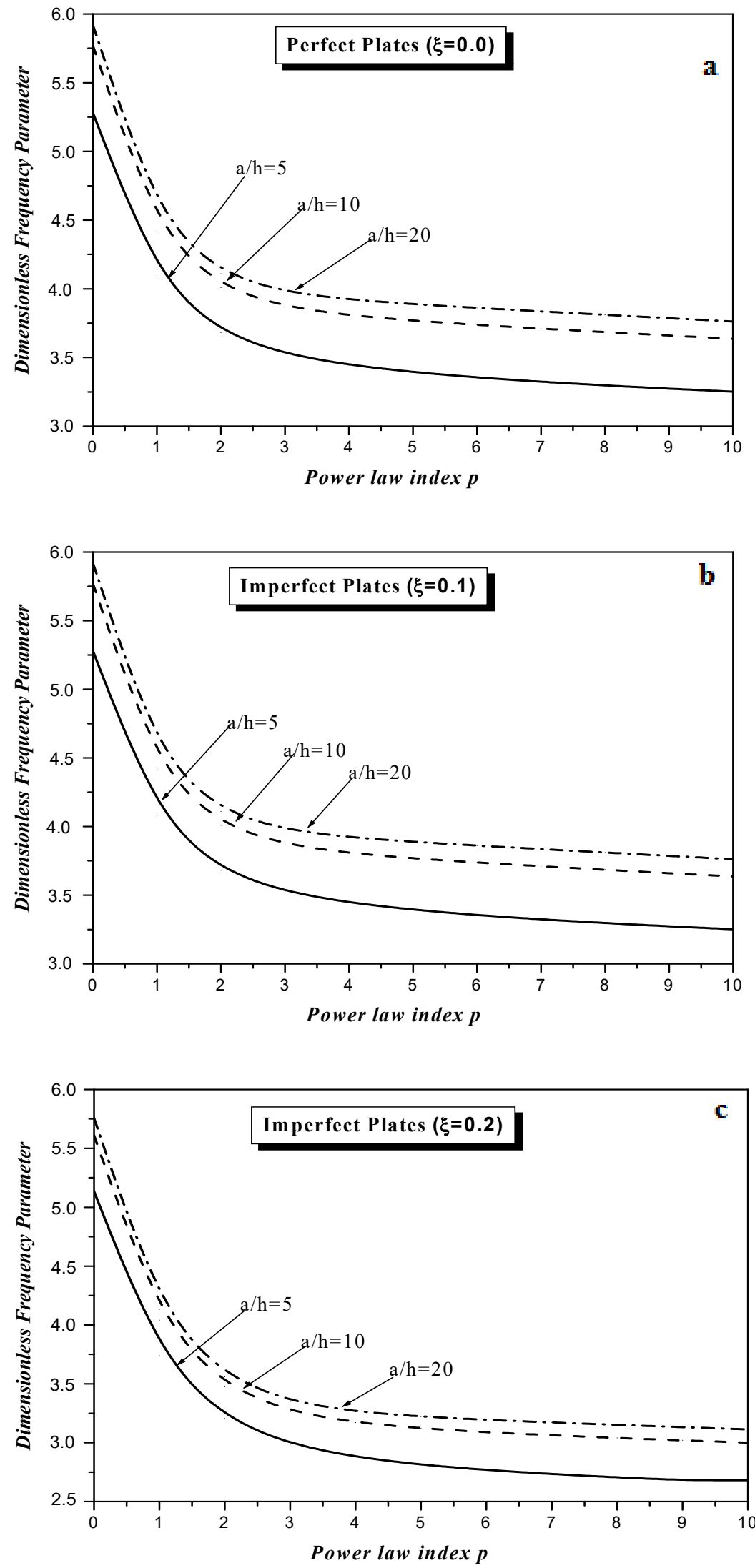

Figure 4. The dimensionless frequency $\bar{\omega}$ vs. the power index $p$ for FG plates with a different porosity factor $\xi$ and thickness ratio $a / h$. 


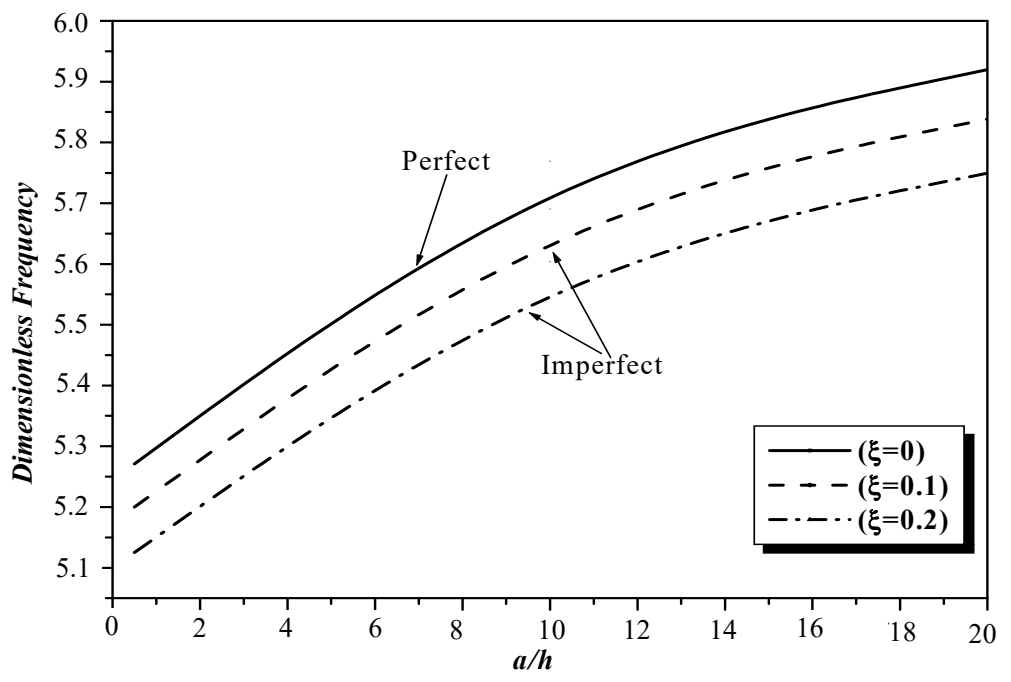

Figure 5. The dimensionless frequency $\bar{\omega}$ vs. the thickness ratio $a / h$ for perfect and imperfect plates.

\section{Conclusions}

This work proposes a four-variable HSDT to analyze the free vibration response of porous square and rectangular FG plates with a different porosity level, $\xi$, and applies the Hamilton's principle to determine the equations of motion. The problem is tackled theoretically, where a Navier-type solution is enforced to determine the vibration response, while checking for its sensitivity to different input mechanical and geometrical parameters, namely, the power index, the porosity factor, the length-to-thickness ratio and the in-plane rational geometry. The proposed approach is verified as being very accurate with respect to other models available in the literature, even when structures are made of complicated materials including porosities. Based on a systematic investigation, the predictions based on perfect structures could be inaccurate and tend to overestimate the vibration frequencies. The vibration response of the structure, indeed, is demonstrated to be significantly affected by the volume fraction distributions (with a percentage variation of up to $40 \%$ ), slenderness ratios (about 10\%) and porosities (about 10-20\%), whose analytical results could be of great interest for the design purposes of materials and structural components, as well as for further computational studies.

Author Contributions: Conceptualization, S.M., H.M.A., B.H., R.D. and F.T.; Data curation, F.T.; Formal analysis, S.M., H.M.A., B.H., R.D. and F.T.; Investigation, S.M., H.M.A., B.H., R.D. and F.T.; Methodology, R.D. and F.T.; Supervision, R.D. and F.T.; Validation, R.D. and F.T.; Writing-original draft, S.M., H.M.A. and B.H.; Writing-review \& editing, R.D. and F.T. All authors have read and agreed to the published version of the manuscript.

Funding: This research received no external funding.

Conflicts of Interest: The authors declare no conflict of interest.

\section{References}

1. Koizumi, M. FGM activities in Japan. Compos. Part B Eng. 1997, 28, 1-4. [CrossRef]

2. Dehnavi, F.N.; Parvizi, A. Investigation of thermo-elasto-plastic behavior of thick-walled spherical vessels with inner functionally graded coatings. Meccanica 2017, 19, 2421-2438. [CrossRef]

3. Wang, Q.; Shi, J.; Zhang, L.; Tsutsumi, S.; Feng, J.; Ma, N. Impacts of laser cladding residual stress and material properties of functionally graded layers on titanium alloy sheet. Addit. Manuf. 2020, 35, 101303. [CrossRef]

4. Huang, S.; Guo, L.; Zhang, L.; Zhang, Y.; Pan, H. The interface crack problem under steady heat flux for a functionally graded coating-substrate structure with general coating properties. Theor. Appl. Fract. Mech. 2020, 109, 102675. [CrossRef]

5. Dubey, A.; Jaiswal, S.; Haldar, S.; Roy, P.; Lahiri, D. Functionally gradient magnesium-based composite for temporary orthopaedic implant with improved corrosion resistance and osteogenic properties. Biomed. Mater. 2021, 16, 015017. [CrossRef]

6. Mondal, K.; Nuñez, L.; Downey, C.M.; Van Rooyen, I.J. Thermal barrier coatings overview: Design, manufacturing, and applications in high-temperature industries. Ind. Eng. Chem. Res. 2021, 60, 6061-6077. [CrossRef] 
7. Khaleghi, F.; Tajally, M.; Emadoddin, E.; Mohri, M. Functionally-graded shape memory alloy by diffusion annealing of palladiumcoated NiTi plates. Met. Mater. Int. 2017, 23, 915-922. [CrossRef]

8. Sun, Y.; Chen, J.; Li, S.R. Finite element analysis for the buckling of functionally graded material plates based on physical neutral surface. Jisuan Lixue Xuebao/Chin. J. Comput. Mech. 2020, 37, 560-566.

9. Benyamina, A.B.; Bouderba, B.; Saoula, A. Bending response of composite material plates with specific properties, case of a typical fgm "ceramic/metal" in thermal environments. Period. Polytech. Civil Eng. 2018, 62, 930-938. [CrossRef]

10. Smith, J.A.; Mele, E.; Rimington, R.P.; Capel, A.J.; Lewis, M.P.; Silberschmidt, V.V.; Li, S. Polydimethylsiloxane and poly(ether) ether ketone functionally graded composites for biomedical applications. J. Mech. Behav. Biomed. Mater. 2019, 93, 130-142. [CrossRef]

11. Rousseau, C.E.; Chalivendra, V.B.; Tippur, H.V.; Shukla, A. Experimental Fracture Mechanics of Functionally Graded Materials: An Overview of Optical Investigations. Exp. Mech. 2010, 50, 845-865. [CrossRef]

12. Tornabene, F.; Liverani, A.; Caligiana, G. FGM and laminated doubly curved shells and panels of revolution with a free-form meridian: A 2-D GDQ solution for free vibrations. Int. J. Mech. Sci. 2011, 53, 446-470. [CrossRef]

13. Vel, S.S.; Batra, R.C. Three-dimensional exact solution for the vibration of functionally graded rectangular plates. J. Sound Vib. 2004, 272, 703-730. [CrossRef]

14. Ferreira, A.J.M.; Batra, R.C.; Roque, C.M.C.; Qian, L.F.; Jorge, R.M.N. Natural frequencies of functionally graded plates by a meshless method. Compos. Struct. 2006, 75, 593-600. [CrossRef]

15. Qian, L.F.; Batra, R.C.; Chen, L.M. Static and dynamic deformations of thick functionally graded elastic plates by using higherorder shear and normal deformable plate theory and meshless local Petrov-Galerkin method. Compos. Part B Eng. 2004, 35, 685-697. [CrossRef]

16. Tornabene, F.; Brischetto, S.; Fantuzzi, N.; Viola, E. Numerical and exact models for free vibration analysis of cylindrical and spherical shell panels. Compos. Part B Eng. 2015, 81, 231-250. [CrossRef]

17. Tornabene, F.; Fantuzzi, N.; Bacciocchi, M.; Dimitri, R. Free vibrations of composite oval and elliptic cylinders by the generalized differential quadrature method. Thin Wall Struct. 2015, 97, 114-129. [CrossRef]

18. Rezaei, A.S.; Saidi, A.R. Application of Carrera Unified Formulation to study the effect of porosity on natural frequencies of thick porous-cellular plates. Compos. Part B Eng. 2016, 91, 361-370. [CrossRef]

19. Rezaei, A.S.; Saidi, A.R. On the effect of coupled solid-fluid deformation on natural frequencies of fluid saturated porous plates. Eur. J. Mech. A. Solids 2017, 63, 99-109. [CrossRef]

20. Kamranfard, M.R.; Saidi, A.R.; Naderi, A. Analytical solution for vibration and buckling of annular sectorial porous plates under in-plane uniform compressive loading. Proc. Inst. Mech. Eng. Part C J. Mech. Eng. Sci. 2017, 232, 2211-2228. [CrossRef]

21. Benachour, A.; Tahar, H.D.; Atmane, H.A.; Tounsi, A.; Ahmed, M.S. A four variable refined plate theory for free vibrations of functionally graded plates with arbitrary gradient. Compos. Part B Eng. 2011, 42, 1386-1394. [CrossRef]

22. Belabed, Z.; Houari, M.S.A.; Tounsi, A.; Mahmoud, S.R.; Bég, O.A. An efficient and simple higher order shear and normal deformation theory for functionally graded material (FGM) plates. Compos. Part B Eng. 2014, 60, 274-283. [CrossRef]

23. Bîrsan, M.; Altenbach, H.; Sadowski, T.; Eremeyev, V.A.; Pietras, D. Deformation analysis of functionally graded beams by the direct approach. Compos. Part B Eng. 2012, 43, 1315-1328. [CrossRef]

24. Bîrsan, M.; Sadowski, T.; Marsavina, L.; Linulc, E.; Pietras, D. Mechanical behavior of sandwich composite beams made of foams and functionally graded materials. Int. J. Solids Struct. 2013, 50, 519-530. [CrossRef]

25. Vyacheslav Burlayenko, N.; Sadowski, T. Free vibrations and static analysis of functionally graded sandwich plates with three-dimensional finite elements. Meccanica 2020, 55, 815-832. [CrossRef]

26. Bîrsan, M.; Pietras, D.; Sadowski, T. Determination of effective stiffness properties of multilayered composite beams. Contin. Mech. Thermodyn. 2021, 33, 1781-1803. [CrossRef]

27. Vyacheslav Burlayenko, N.; Sadowski, T.; Altenbach, H. Efficient free vibration analysis of FGM sandwich flat panels with conventional shell elements. Mech. Adv. Mater. Struct. 2021. [CrossRef]

28. Shimpi, R.P. Refined plate theory and its variants. AIAA J. 2002, 40, 137-146. [CrossRef]

29. Merdaci, S.; Tounsi, A.; Houari, M.S.A.; Mechab, I.; Hebali, H.; Benyoucef, S. Two new refined shear displacement models for functionally graded sandwich plates. Arch. Appl. Mech. 2011, 81, 1507-1522. [CrossRef]

30. Ameur, M.; Tounsi, A.; Mechab, I.; Adda Bedia, E.A. A New Trigonometric Shear Deformation Theory for Bending Analysis of Functionally Graded Plates Resting on Elastic Foundations. KSCE J. Civ. Eng. 2011, 15, 1405-1414. [CrossRef]

31. Tounsi, A.; Houari, M.S.A.; Benyoucef, S.; Adda Bedia, E.A. A refined trigonometric shear deformation theory for thermoelastic bending of functionally graded sandwich plates. Aerosp. Sci. Technol. 2013, 24, 209-220. [CrossRef]

32. Mohamed, Z.; Tounsi, A.; Houari, M.S.A.; Adda Bedia, E.A.; Anwar Bég, O. Bending analysis of FGM plates under hygro-thermomechanical loading using a four variable refined plate theory. Aerosp. Sci. Technol. 2014, 34, 24-34.

33. Zhu, J.; Lai, Z.; Yin, Z.; Jeon, J.; And Lee, S. Fabrication of $\mathrm{ZrO}_{2}-\mathrm{NiCr}$ functionally graded material by powder metallurgy. Mater. Chem. Phys. 2001, 68, 130-135. [CrossRef]

34. Wattanasakulpong, N.; And Ungbhakorn, V. Linear and nonlinear vibration analysis of elastically restrained ends FGM beams with porosities. Aerosp. Sci. Technol. 2014, 32, 111-120. [CrossRef]

35. Magnucka-Blandzi, E.; Magnucki, K. Effective design of a sandwich beam with a metal foam core. Thin-Walled Struct. 2007, 45, 432-438. [CrossRef] 
36. Biot, M. Theory of buckling of a porous slab and its thermoelastic analogy. J. Appl. Mech. 1964, 31, 194-198. [CrossRef]

37. Detournay, E.; Cheng, A.H.D. Fundamentals of poroelasticity. In Comprehensive Rock Engineering: Principles, Practice and Projects; Chapter 5; Pergamon Press: Oxford, UK, 1993; Volume 2.

38. Jabbari, M.; Mojahedin, A.; Khorshidvand, A.; Eslami, M. Buckling analysis of a functionally graded thin circular plate made of saturated porous materials. J. Eng. Mech. 2014, 140, 287-295. [CrossRef]

39. Ait Yahia, S.; Ait Atmane, H.; Houari, M.S.A.; Tounsi, A. Wave propagation in functionally graded plates with porosities using various higher-order shear deformation plate theories. Struct. Eng. Mech. 2015, 53, 1143-1165. [CrossRef]

40. Mouaici, F.; Benyoucef, S.; Ait Atmane, H.; Tounsi, A. Effect of porosity on vibrational characteristics of non-homogeneous plates using hyperbolic shear deformation theory. Wind Struct. 2016, 22, 429-454. [CrossRef]

41. Merdaci, S. Analysis of Bending of Ceramic-Metal Functionally Graded Plates with Porosities Using of High Order Shear Theory. Adv. Eng. Forum. 2018, 30, 54-70.

42. Merdaci, S.; Belghoul, H. High Order Shear Theory for Static Analysis Functionally Graded Plates with Porosities. C. R. Mec. 2019, 347, 207-217. [CrossRef]

43. Merdaci, S.; Mostefa, A.H. Influence of porosity on the analysis of sandwich plates FGM using of high order shear-deformation theory. Frat. Int. Strutt. 2020, 14, 199-214. [CrossRef]

44. Merdaci, S.; Mostefa, A.H.; Beldjelili, Y.; Mohamed, M.; Boutaleb, S.; Hellal, H. Analytical solution for static bending analysis of functionally graded plates with porosities. Frat. Int. Strutt. 2021, 15, 65-75.

45. Reddy, J.N. Energy Principles and Variational Methods in Applied Mechanics; Wiley: New York, NY, USA, 2002.

46. Merdaci, S. Free Vibration Analysis of Composite Material Plates “Case of a Typical Functionally Graded FG Plates Ceramic/Metal with Porosities". Nano Hybrids Compos. (NHC) 2019, 25, 69-83. [CrossRef]

47. Merdaci, S.; Mostefa, A.H.; Boutaleb, S.; Hellal, H. Free Vibration Analysis of Functionally Graded FG Nano-Plates with Porosities. J. Nano Res. 2020, 64, 61-74.

48. Arshid, E.; Khorshidvand, A.R. Free vibration analysis of saturated porous FG circular plates integrated with piezoelectric actuators via differential quadrature method. Thin Wall. Struct. 2018, 125, 220-233. [CrossRef]

49. Li, H.; Pang, F.; Chen, H.; Du, Y. Vibration analysis of functionally graded porous cylindrical shell with arbitrary boundary restraints by using a semi analytical method. Compos. Part B 2019, 164, 249-264. [CrossRef]

50. Xue, Y.; Jin, G.; Ma, X.; Chen, H.; Ye, T.; Chen, M.; Zhang, Y. Free vibration analysis of porous plates with porosity distributions in the thickness and in-plane directions using isogeometric approach. Int. J. Mech. Sci. 2019, 152, 346-362. [CrossRef]

51. Mashat, D.S.; Zenkour, A.M.; Radwan, A.F. A quasi-3D higher-order plate theory for bending of FG plates resting on elastic foundations under hygro-thermo-mechanical loads with porosity. Eur. J. Mech. A. Solid 2020, 82, 103985. [CrossRef]

52. Xie, K.; Wang, Y.; Niu, H.; Chen, H. Large-amplitude nonlinear free vibrations of functionally graded plates with porous imperfection: A novel approach based on energy balance method. Compos. Struct. 2020, 246, 112367. [CrossRef]

53. Zhang, Y.; Jin, G.; Chen, M.; Ye, T.; Yang, C.; Yin, Y. Free vibration and damping analysis of porous functionally graded sandwich plates with a viscoelastic core. Compos. Struct. 2020, 244, 112298. [CrossRef]

54. Belarbi, M.O.; Khechai, A.; Bessaim, A.; Houari, M.S.A.; Garg, A.; Hirane, H.; Chalak, H.D. Finite element bending analysis of symmetric and non-symmetric functionally graded sandwich beams using a novel parabolic shear deformation theory. Proc. Inst. Mech. Eng. Part L J. Mater. Des. Appl. 2021, 235, 2482-2504. [CrossRef]

55. Belarbi, M.O.; Zenkour, A.M.; Tati, A.; Salami, S.J.; Khechai, A.; Houari, M.S.A. An efficient eight-node quadrilateral element for free vibration analysis of multilayer sandwich plates. Int. J. Numer. Methods Eng. 2021, 122, 2360-238715. [CrossRef]

56. Daikh, A.A.; Houari, M.S.A.; Belarbi, M.O.; Chakraverty, S.; Eltaher, M.A. Analysis of axially temperature-dependent functionally graded carbon nanotube-reinforced composite plates. Eng. Comput. 2021. [CrossRef]

57. Kumar, V.; Singh, S.J.; Saran, V.H.; Harsha, S.P. Vibration characteristics of porous FGM plate with variable thickness resting on Pasternak's foundation. Eur. J. Mech. A. Solids 2021, 85, 104124. [CrossRef]

58. Kumar Sah, S.; Ghosh, A. Influence of Porosity Distribution on Free Vibration and Buckling Analysis of Multi- Directional Functionally Graded Sandwich Plates. Compos. Struct. 2021, 279, 114795. [CrossRef]

59. Tornabene, F.; Viscoti, M.; Dimitri, R.; Antonietta Aiello, M. Higher-order modeling of anisogrid composite lattice structures with complex geometries. Eng. Struct. 2021, 244, 112686. [CrossRef]

60. Van Vinh, P.; Huy, L.Q. Finite element analysis of functionally graded sandwich plates with porosity via a new hyperbolic shear deformation theory. Def. Technol. 2021. [CrossRef]

61. Yin, Z.; Gao, H.; Lin, G. Bending and free vibration analysis of functionally graded plates made of porous materials according to a novel the semi-analytical method. Eng. Anal. Bound. Elem. 2021, 133, 185-199. [CrossRef]

62. Zghal, S.; Ataoui, D.; Dammak, F. Free vibration analysis of porous beams with gradually varying mechanical properties. Proc. Inst. Mech. Eng. Part M J. Eng. Marit. Environ. 2021. [CrossRef]

63. Belarbi, M.O.; Houari, M.S.A.; Hirane, H.; Daikh, A.A.; Bordas, S.P.A. On the finite element analysis of functionally graded sandwich curved beams via a new refined higher order shear deformation theory. Compos. Struct. 2022, 279, 114715. [CrossRef]

64. Merdaci, S.; Hadj, M.A.; Merazi, M.; Belghoul, H.; Hellal, H.; Boutaleb, S. Effects of even pores distribution of functionally graded plate porous rectangular and square. Procedia Struct. Integr. 2020, 26, 35-45.

65. Rezaei, A.S.; Saidi, A.R.; Abrishamdari, M.; Pour Mohammadi, M.H. Natural frequencies of functionally graded plates with porosities via a simple four variable plate theory: An analytical approach. Thin-Walled Struct. 2017, 120, 366-377. [CrossRef] 
66. Askari, M.; Saidi, A.R.; Rezaei, A.S.; Badizi, M.A. Navier-type Free Vibration Analysis of Porous Smart Plates According to Reddy's Plate Theory. In Proceedings of the First International Conference on Mechanics of Advanced Materials and Equipment, Ahvaz, Iran, 31 January 2018

67. Shi, J.W.; Nakatani, A.; Kitagawa, H. Vibration analysis of fully clamped arbitrarily laminated plate. Compos. Struct. 2004, 63, 115-122. [CrossRef]

68. Shi, J.W.; Nakatani, A.; Kitagawa, H. Approximate vibration analysis of laminated curved panel using higher-order shear deformation theory. Acta Mech. Sinica 2004, 20, 238-246. 